\title{
Pre-K Partnership
}

\section{How One Library and One Public School Increased Parent Engagement}

KRISTEE ROCHAALDRICH

$\mathrm{P}$ re-K seems to be the new kindergarten. Parents and caregivers are faced with increasing pressure to ensure their children are school ready.

Every parent and caregiver possesses these skills; however, a little extra support and guidance can go a long way in a child's literacy development. Pre-K is a great place for children to build and learn new literacy and social emotional skills. Teachers are there to help the families begin navigating the school system and to give their children the building blocks to become successful lifelong learners. However, this process begins long before a child enters school. Often, the first time children and families are exposed to these skills is at their local library, either through activities geared towards families or through partnerships with pre-K and daycare classrooms.

In New York City, even with various schools and daycares within walking distance of the New York Public Library's (NYPL) eighty-eight branches in the Bronx, Manhattan, and Staten Island, forming consistent partnerships with schools and daycares can be difficult. Conducting outreach to teachers requires a delicate balance of emphasizing the many services the library offers without being too pushy. And of course, every school and daycare is different-some are welcoming and others never respond to calls or emails. Despite the mixed responses I have received when conducting outreach, there is always one aspect of the library that seems to pique teachers' interests.

Libraries are uniquely positioned as a community anchor and already have the trust of families. Librarians and library staff build lasting connections with each patron who walks in the door. Often, librarians watch children grow from infants at baby storytime into high school students using the library's resources to write research papers.
They know the child's interests-they probably even helped the child discover some interests-as well as the family's larger concerns. This familiarity grows out of the type of trust and support a school cannot regularly give to every student and family. It is the foundation of the type of relationship our libraries are founded on.

In early summer 2015, I met with pre-K teacher Nancy Jalowiecki, after Inwood Library Branch Manager Danita Nichols said that Nancy had been using the library for classroom resources. Danita thought the two of us would have a lot to talk about given our shared passion for early childhood education. Fortunately for me, Nancy welcomed the library with open arms.

One of the first things we discussed was parent engagement among her class and the other four pre-K classes at her school, which Nancy described as extremely low. Later, in working with the Department of Education (DOE), we confirmed that parent engagement throughout the city's universal pre-K program, "Pre-K for All," was often lacking. Around the same time, I attended an "Every Child Ready to Read 2" training with

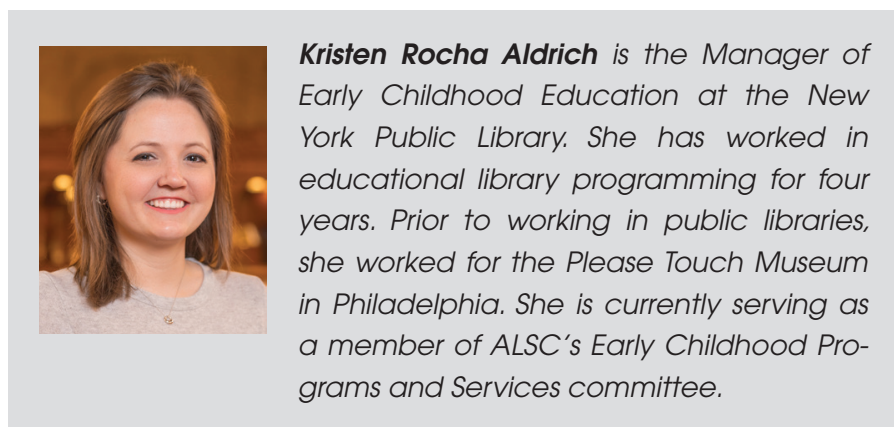




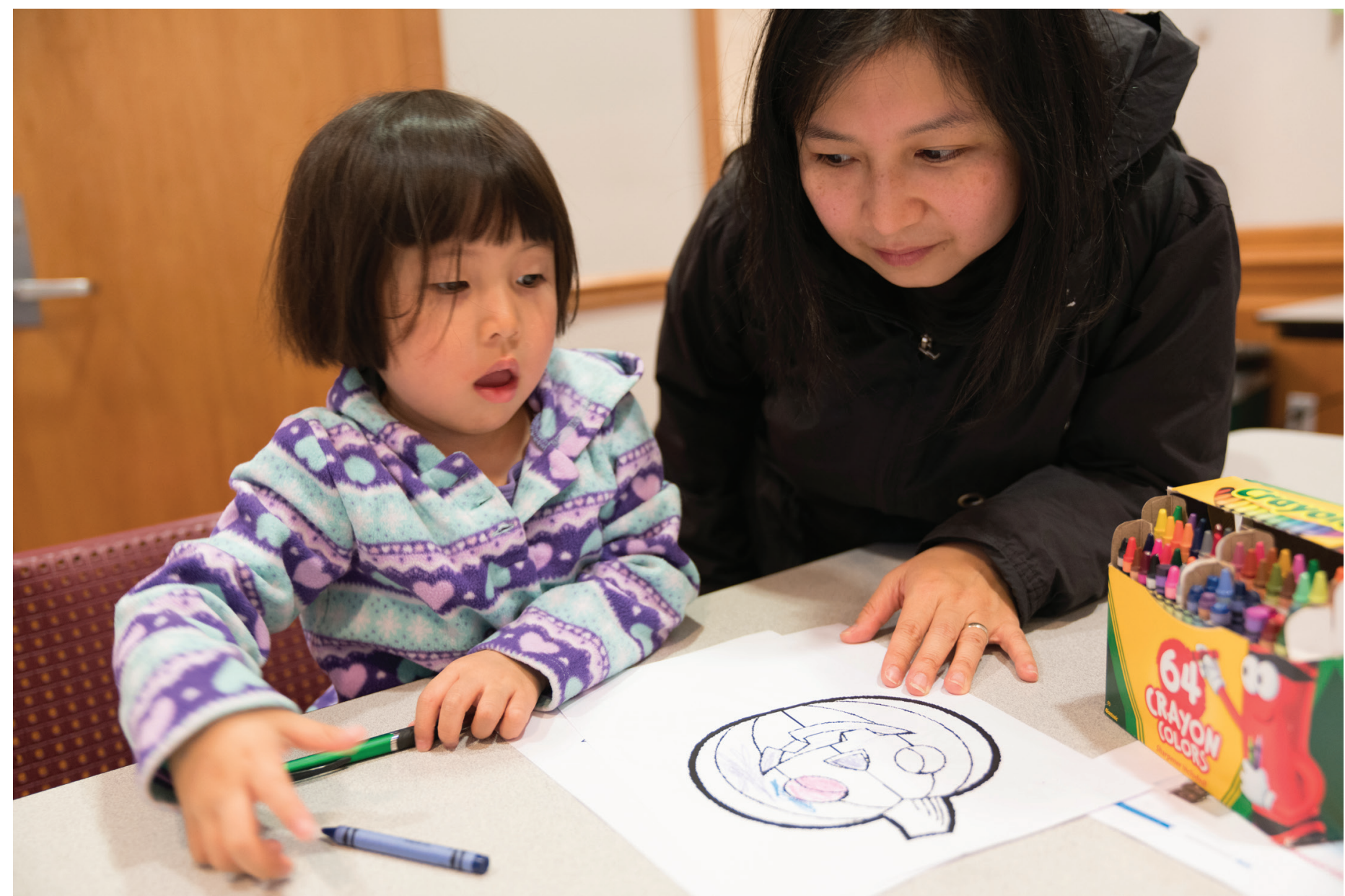

A mother and her daughter spend time at a coloring themed passport station to work on the daughter's fine motor skills.

instructor Saroj Ghoting, and began looking for a way to reach parents through family literacy workshops. After speaking with Nancy, it occurred to me that NYPL was the perfect match for her school, PS 98.

The Inwood Library piloted a family literacy workshop series at PS 98 starting in October 2015, which ran for eight months throughout the school year and began again in fall 2016. The library visits on the first Wednesday of each month for thirtyfive minutes at the 8:10 a.m. drop-off time.

While the students are eating breakfast in the cafeteria, the library provides breakfast and coffee for the parents and caregivers as they listen to the library staff and the pre-K teachers co-deliver a bilingual (English/Spanish) workshop. The content is based on a parent survey the school conducts the previous year, eliciting the topics for which the parents need more support when helping their children outside of school.

Nancy and I co-developed and delivered all of the content, along with Inwood's children's librarian, Rachel Skinner-O'Neill. Topics include Creating a Literacy-Friendly Household, Free Neighborhood Resources, Language and Child Development, Math and Literacy, and Getting Ready for Kindergarten. At the end of each session, parents and caregivers are given a bilingual handout of the topic covered to take home and practice with their child.

At the first session, we focused on creating a community of parents and caregivers by asking them to get to know and support one another. This set the tone for the school year. We also gave out Early Literacy Kits, which included tip sheets, an $A B C$ Read with Me in NYC book, a growth chart, and a branch event calendar.

The last session was a celebration, honoring the parents' and caregivers' commitment to their children's learning. Each family was given a picturebook and school supplies. Nancy also developed certificates of completion for each parent and caregiver who participated in five or more workshops.

While the content shared at each of the workshops was not groundbreaking, the two most frequent comments we received were:

1. Parents and caregivers were thrilled to hear that the simple things they already do, like talking to their child on the subway, are actually helping their child learn and grow. Their parenting skills are validated. 
2. They felt empowered to know they don't have to be an education expert to give their child the tools needed for success.

It is amazing, for example, to watch a room full of parents and caregivers first recite the words of "Twinkle, Twinkle, Little Star," and then sing it to demonstrate how singing helps their child develop phonological awareness. So simple, yet incredibly effective.

After the workshops, the librarians frequently follow up with class visits for storytimes. After school, the families can also visit the library to browse and check out books. The library's designated Pre-K for All Book Corner houses all of the books from the DOE's Pre-K for All Units of Study booklists, which NYPL co-created with the DOE. Thus, the library provides a holistic approach by supporting parents and caregivers, providing literacy activities directly to the children, and inviting families back to the library to supplement their children's learning at school through further access to resources and literacy programming.

Last school year, between thirty and fifty parents and caregivers consistently attended each workshop. In the 2015-2016 school year, parent engagement for PS 98 pre-K classrooms increased by thirty-six percent, which the school attributed solely to the new partnership with NYPL.

There are similar numbers of parents and caregivers participating this school year as well. The content of the workshops was edited to include interactive activities for each workshop and increase the focus on child development and kindergarten readiness, a request made by the parents and caregivers.

As I began sharing this partnership success with colleagues throughout NYPL, and as more branches were required to offer family literacy workshops, many branches were quick to adapt the Inwood/PS 98 partnership model into something that works for their specific communities. Although the Inwood/PS 98 model has been successful for us, it may not work in every context. For example, at some schools, parents cannot stay for thirty-five minutes after drop off. Other branches determine that it is too limiting to hold the workshops for just pre-K parents and caregivers. In these cases, individual branches have been able to develop early literacy programs that are suited to the families in their communities.
NYPL's Harlem Library, for example, adapted the pre-K workshop content into a "passport-style" workshop, where children and their parents and caregivers visit different tables throughout the branch. Each table addresses a skill a child needs to enter kindergarten prepared. The parents and caregivers and child complete the activity together, get a stamp in their passport, and move to the next station.

NYPL's Morrisania branch took the pre-K workshop content on the road to local homeless shelters. Many other branches host "after-hours" family literacy workshops, and offer dinner and childcare for the families attending the workshop-one librarian will offer a storytime to the children, while the other delivers the workshop to the parents and caregivers. At the end, the parents and caregivers and children come back together to practice literacy-building activities.

No matter how Family Literacy Workshops are hosted, these four core components make them successful:

- Outreach, outreach, outreach. Even if you do not host your workshop with a pre-K classroom, school outreach is always a great way to advertise your programming and build relationships with the teachers.

- Food. If there is food, people will come.

- Childcare. Providing childcare means that parents and caregivers do not have to find a babysitter to attend a library workshop.

- Adaptability. You need to know what your community and pre-K teachers need, not just what you are interested in providing them.

It may take time to find the right fit for your community, but it is worth it. No matter the content covered in the workshop, the community you are helping create for the families and schools is invaluable, whether it's for two families or fifty families. The library acts as a home-school-community connector and is an unwavering center of support for all families. $\lesssim$ 